\title{
INIBIÇÃO DO CRESCIMENTO MICELIAL E GERMINAÇÃO DE Colletotrichum gloeosporioides NA SERINGUEIRA PELO ÓLEO DE NEEM
}

(Azadirachta indica)

\author{
SILVA, Rosemeire Alves ${ }^{1}$ \\ PEREIRA, Regina Eli de Almeida ${ }^{2}$ \\ NAKANO, Margareti Aparecida Stachissini ${ }^{3}$
}

\begin{abstract}
RESUMO: O óleo extraído da árvore Nim (Azadirachta indica) tem sido usado recentemente como inseticida, fungicida e adubo orgânico. O trabalho avaliou o efeito fungitóxico do óleo de Neem (Neem ISLA), na inibição do crescimento micelial e germinação de conídios in vitro de Colletotrichum gloeosporioides, como forma alternativa de controle da antracnose em seringueira. Os tratamentos testados foram: 0, 10, 50, 100 e $200 \mu \mathrm{g} / \mathrm{ml} \mathrm{de}$ ingrediente ativo Azadiractinia. Os isolados foram obtidos da variedade RRIM 600 da Fazenda Santa Clara, SP. Para avaliar a sensibilidade micelial incorporou-se o óleo de Neem ao meio de cultura BDA de acordo com as concentrações, mais um disco de $4 \mathrm{~mm}$ de micélio ativo do fungo por placas de Petri $\left(25^{\circ} \mathrm{C}, 12 / 12 \mathrm{~h}\right.$ por 7 dias $)$. Avaliou-se o crescimento micelial em 4 sentidos perpendiculares. Usou-se suspensão de $5 \times 10^{4}$ conídio em água destilada + óleo, para avaliar a inibição da germinação conidial. As amostras avaliadas tinham $15 \mu$ de suspensão oleosa $+15 \mu$ de suspensão de conídios, colocadas em lâminas escavadas e incubadas a $20^{\circ} \mathrm{C}$ sob luz contínua durante 12 horas. Foi determinada a germinação de 100 conídios para cada repetição. O melhor resultado obtido foi na concentração de $200 \mu \mathrm{g}$, com $60 \%$ para inibição micelial e $53,8 \%$ de inibição da germinação.
\end{abstract}

Palavras-chave: Antracnose. Seringueira. Controle biológico. Nim.

SUMMARY: The oil extracted from Azadirachta indica has been recently used as insecticide, fungicide and fertilizer. This study was evaluate the antifungal effect of Neem Oil ISLA in mycelial growth and conidial germination inhibition, in vitro, using Colletotrichum gloeosporioides, as an alternative to control anthracnose in rubber. Five treatments were used: $0,10,50,100$ and $200 \mu \mathrm{g} / \mathrm{ml}$ of Neem Oil. The isolates were obtained from the RIIM 600 variety, from Santa Clara, SP. To evaluate the mycelial sensitivity, it was joined the oil to the medium culture according to the concentrations. Active mycelium disks $(4 \mathrm{~mm})$ of Colletotrichum were placed in Petri dishes $\left(25^{\circ} \mathrm{C}, 12 / 12 \mathrm{~h}\right.$ for 7 days). The mycelial growth was evaluated in 4 perpendicular directions. It was used a conidia suspension with $5 \times 10^{4}$ spore in distilled water + oil. The samples had $15 \mu \mathrm{l}$ of oil solution $+15 \mu \mathrm{l}$ of spore suspension, placed in excavated plates, incubated at $20^{\circ} \mathrm{C}$ under continuous light for 12 hours. The germination of 100 conidia for each repetition was determined. The best result was using the concentration of $200 \mathrm{mg}$, with $60 \%$ of mycelial inhibition and $53.8 \%$ of germination inhibition.

Keywords: Anthracnose. Rubber. Biological control. Nim.

\section{INTRODUÇÃO}

A árvore de Nim (Azadirachta indica) é originária da Índia pertencente à família meliaceae, é usada há séculos no oriente como planta medicinal, e mais recentemente, como inseticida, fungicida e adubo orgânico. A árvore tem porte de 15 a 20 metros de altura. No Brasil, alguns produtores já descobriram o potencial dessa árvore que fornece

\footnotetext{
${ }^{1}$ Bióloga. Laboratório de Fitopatologia, e-mail rosealvesbiologia@yahoo.com.br

${ }^{2}$ Prof ${ }^{a}$. Titular de Fitopatologia da Faculdade Dr. Francisco Maeda - FAFRAM- de Ituverava, SP

${ }^{3}$ Prof $^{\mathrm{a}}$. Assistente. Faculdade Dr. Francisco Maeda - FAFRAM- de Ituverava, SP
} 
matéria prima para a fabricação de diversos produtos, sejam medicinais, cosméticos ou de aplicação agropecuária. Os principais ingredientes ativos do óleo de Neem pertencem a uma classe de produtos naturais conhecidos como limonóides (ISLA, 2010)

Seus principais elementos químicos são uma mistura de 3ou 4 compostos correlatos, que podem ser modificados em mais de 20 outros menores, porém não menos ativos. No geral, esses compostos pertence à classe dos produtos naturais conhecidos por triterpenos, mais especificamente limonóides. De fato, pelo menos 9 limonóides de Nim têm demonstrado habilidade em bloquear o desenvolvimento de pragas agrícolas. Dentre esses, o limonóide ou tetranortriterpenóide azadiractina é o mais estudado e mais potente. Estudos têm indicado quelimonóides presentes na planta e possuem diversos mecanismos e sítios de ação, causando efeito anti alimentar (MARTINEZ, 2002).

O extrato de Nim causa efeito repelente de postura de ovos, efeito regulador do crescimento, interferência nas funções bioquímicas e fisiológicas, efeitos sobre a reprodução, e em certos casos, a morte. Outros estudos demonstraram uma ação direta, inibindo a motilidade por meio de efeitos citotóxicos e promovendo inibição da síntese de quitina.( MOSSINI; KEMMELMEIER, 2004).

Testes envolvendo o uso de extratos de folhas em cultura líquida mostraram inibição do crescimento vegetativo de Fusarium oxysporum f. sp. ciceri, Rhizoctonia solani, Sclerotium rolfsii, e Sclerotinia sclerotiorum, e têm confirmado a atividade antifúngica dos extrato de Nim com efeitos fungitóxicos in vitro e efeito fungistático com a paralisação do crescimento micelial sobre fungos fitopatogênicos, dentre eles Aspergillus flavus, Diaporthe phascolorum, Fusarium oxysporum, Fusarium solani, Fusarium verticillioides e Sclerotinia sclerotiorum. Já a aplicações de suspensão aquosa de extratos de Nim, por meio de pulverização foliar, sobre tomate e pimenta, em casa de vegetação e no campo, não só reduziram a incidência de doença como também aumentaram o rendimento, produzindo frutos mais saudáveis sem causar efeitos fitotóxicos. (MOSSINI; KEMMELMEIER, 2004).

Técnicas como o emprego de extratos vegetais, aminoácidos, microorganismos e, agora óleos essenciais, enquadram em estratégias de controle biológico de patógenos de planta segundo Bastos et al. (2004).

$\mathrm{O}$ gênero Hevea pertencente à família Euphorbiaceae. Todas as espécies são lenhosas, arbóreas, em geral árvores medianas e até grandes; alguns exemplares podem atingir até $50 \mathrm{~m}$ de altura na floresta alta (GASPAROTTO et al., 1997) .

No Brasil, a seringueira é cultivada da Região Norte até o norte do Estado do todos os Estados das Regiões Sudeste e Centro-Oeste. No Nordeste, além da Bahia, 
existem cultivos em exploração no estado de Pernambuco. (GASPAROTTO et al.; 1997) Na América Latina, entre os diversos fatores que afetam o desenvolvimento e a produção da seringueira (Hevea spp.) as doenças ocupam lugar de destaque. O primeiro surto de antracnose em seringueira no Estado de São Paulo foi relatado em 1987, no município de Porto Feliz, causada por Colletotrichum gloeosporioides, provocando mancha e queda de folhas, morte de inflorescência e seca de ponteiros. Em junho de 1988, no município de Tupã, constatou-se pela primeira vez no Brasil o patógeno no painel de sangria, provocando lesões e exudação de látex, comprovando que outras partes da planta estão sujeitas ao ataque do fungo (SILVEIRA et al., 1989).

Em levantamentos efetuados, com a verificação de sintomas e a presença do patógeno, verificou-se que o patógeno está amplamente disseminado e que tem uma importância muito grande para a cultura, pelos danos causados (GASPAROTTO et al., 1990)

Silveira et al. (1989) atentam para não se iniciar a sangria nos meses de baixa temperatura (abril - setembro), nem se processar a mesma em plantios consorciados com cafezais, devido ás condições microclimáticas serem propícias ao desenvolvimento da doença. O controle adotado até hoje são os convencionais com a utilização de fungicidas a base de Chorothalonil + tiofanato metílico, numa dose de 2,5g/L do princípio ativo, aplicado semanalmente, em pulverização ou em pincelamento em toda a superfície do painel (FURTADO et al., 1991)

O presente trabalho teve como objetivo verificar, in vitro, o efeito fungitóxico do óleo de Azadirachta indica sobre C. gloeosporioides, como alternativa de controle da antracnose em plantas de seringueira.

\section{MATERIAL E MÉTODOS}

O efeito de diferentes concentrações $(0,10,50,100,200 \mu \mathrm{g} / \mathrm{ml})$ de óleo de Neem (Neem ISLA) no controle de Colletotrichum gloeosporioides foi analisado por meio de testes in vitro, realizados no laboratório de Fitopatologia da Faculdade Dr. Francisco Maeda, em Ituverava, SP, no período de 04/07/2009 à 08/08/2009. Os isolados foram obtidos de folhas com sintomas, de seringueira da variedade RRIM 600 adquiridos na propriedade Fazenda Santa Clara, Capivari da Mata, distrito de Ituverava - SP. As folhas foram transportadas para o laboratório de fitopatologia, e mantidos em câmara úmida por $48 \mathrm{~h}$ até a esporulação do patógeno. Em seguida foi feito o isolamento direto em meio BDA (Batata, Dextrose e Ágar) para obtenção de cultura pura; um disco da cultura foi colocado 
em meio aveia + ágar e mantidos a $20^{\circ} \mathrm{C}$ com fotoperiodo de $12 \mathrm{~h}$ luz e $12 \mathrm{~h}$ escuro, a fim de favorecer a esporulação.

\section{Bioensaio para avaliar a sensibilidade micelial de $C$. gloeosporioides ao óleo de Neem (Neem ISLA)}

O bioensaio foi realizado incorporando-se o óleo de Neem ao meio de cultura BDA fundente $\left(45^{\circ} \mathrm{C}-50^{\circ} \mathrm{C}\right)$ previamente autoclavado, de acordo com as concentrações $0,10,50$, 100, $200 \mu \mathrm{g} / \mathrm{ml}$. Em seguida, foram vertidos em placas de Petri de $9 \mathrm{~cm}$ de diâmetro. Após solidificação do meio, discos de micélio ativo (retirados do meio de cultura com no máximo 7 dias) de Colletotrichum, com $4 \mathrm{~mm}$ de diâmetro, foram colocados no centro das placas de Petri. As placas foram incubadas em BOD (Batata, Dextrose e Ágar) a $25^{\circ} \mathrm{C}$ com fotoperíodo de 12 horas durante 7 dias. O delineamento experimental utilizado foi o Delineamento Inteiramente Casualizado (DIC), com 5 tratamentos com 5 repetições. Avaliou-se os resultados medindo-se o crescimento do diâmetro médio micelial em 4 sentidos perpendiculares, usando uma régua graduada em milímetros (mm), após 7 dias incubação. Os dados foram submetidos à análise estatística por meio do software Estat ${ }^{4} \mathrm{e}$ realizada análise de regressão.

Bioensaio para avaliar a sensibilidade de germinação de conídios de $C$.gloeosporioides ao óleo de Neem

O óleo foi emulsionado em água destilada, obtendo-se as concentrações de 0,10 , $50,100,200 \mu \mathrm{g} / \mathrm{ml}$. Foi feita uma suspensão de conídios na concentração de $5 \times 10^{4}$, coletados de cultura em meio de aveia com 7 dias. Alíquotas de $15 \mu 1$ contendo as concentrações indicadas de óleo foram colocadas em lâminas de vidro escavadas, com cinco repetições, sendo a seguir colocado mais $15 \mu 1$ de suspensão de conídios na concentração de $5 \times 10^{4}$, Após $12 \mathrm{hrs}$ de incubação a $20^{\circ} \mathrm{C}$ sob luz contínua em BOD, foi determinada a germinação dos conídios, contando 100 conídios em cada repetição em microscópio óptico, no aumento de 400x. Foram considerados como conídios germinados aqueles que apresentaram no mínimo tubo germinativo com o dobro do seu tamanho.

\section{RESULTADOS E DISCUSSÃO}

De acordo com os resultados obtidos, observa-se que há efeito do óleo essencial na inibição do crescimento micelial e na germinação de conídios de C. gloeosporioides

${ }^{4}$ ESTAT. Sistema para análise estatística. Departamento de exatas. FCAV/UNESP. Jaboticabal-SP. 
m (Tabela 1).

A inibição do micélio e da germinação ocorreu a partir da concentração de $10 \mu \mathrm{g}$. Analisando-se inicialmente a inibição micelial, pode-se observar que as concentrações de 100 e $200 \mu \mathrm{g}$ obtiveram os melhores resultados com inibição de 58 e $61 \%$ mas não $100 \%$ após 7dias de incubação. Em relação à inibição da germinação, a dose de $200 \mu \mathrm{g}$ apresentou a maior inibição, de 54\%, contudo não diferiu significativamente da concentração de $50 \mu \mathrm{g}$, com $44 \%$, mas diferiu da concentração de $100 \mu \mathrm{g}$ com inibição da germinação em $31 \%$, sendo que após $12 \mathrm{~h}$ havia germinação dos conídio para todas as concentrações e assim comprovando-se, portanto, que não houve efeito fungicida do óleo de Neem, apenas o efeito fungistático e induzindo o fungo apenas na concentração de 200 $\mu \mathrm{g}$ a formar apresório.

Bastos e Albuquerque (2004), testando o óleo essencial de pimenta-de-macaco (Piper aduncum) sobre os conídios de C. musae, observaram 100\% de inibição da germinação Medice et al. (2007), observaram que os óleos essenciais de eucalipto (Corymbia citriodora), citronela (Cymbopogon nardus), nim (Azadirachta indica) e tomilho (Thymus vulgaris) nas concentrações $1 \%, 0,5 \%, 1,0 \%$ e $0,3 \%$ respectivamente, inibiram em 100\% a germinação dos uredinósporos de Phakospsora pachyrhizi, agente causal da ferrugem da soja, em meio água-ágar.

No trabalho realizado por Pereira (2006), onde foi avaliado o efeito de diferentes doses do óleo essencial de tomilho na germinação de Cercospora coffeicola, causador da cercosporiose do café, e os autores observaram que o óleo essencial apresentou efeito tóxico aos conídios, nas concentrações de 500, 1000 e 2000ppm, com redução na germinação de $27 \%, 30 \%$ e $45 \%$, respectivamente.

Tabela 1. Inibição in vitro do crescimento micelial e da germinação de conídios de Colletotrichum gloeosporioides, usando óleo essencial de Neem.

\begin{tabular}{ccc}
\hline $\begin{array}{c}\text { Concentração } \\
\text { óleo }(\boldsymbol{\mu g} / \mathbf{m l})\end{array}$ & $\begin{array}{c}\text { Inibição do } \\
\text { crescimento micelial (\%) }\end{array}$ & $\begin{array}{c}\text { Inibição da } \\
\text { germinação }(\%)\end{array}$ \\
\hline 0 & 0 & 0 \\
10 & $10 \mathrm{a}$ & $21 \mathrm{a}$ \\
50 & $47 \mathrm{~b}$ & $44 \mathrm{bc}$ \\
100 & $58 \mathrm{c}$ & $31 \mathrm{ab}$ \\
200 & $61 \mathrm{c}$ & $54 \mathrm{c}$ \\
Média & 6,32 & 66,2 \\
CV & 4,96 & 14,78 \\
EPM & 0,14 & 4,3 \\
\hline
\end{tabular}

${ }^{1}$ Médias seguidas por letras distintas na vertical diferem entre si pelo teste de Tukey $5 \%$ 
Na Figura 1 está apresentado o comportamento do crescimento micelial pela análise regressão, demonstrando uma tendência de aumento da inibição correspondente ao aumento da dose. Na Figura 2, observa-se a o crescimento micelial da testemunha $(0 \mu \mathrm{g} / \mathrm{mL})$ em comparação ao crescimento do fungo na concentração de $200 \mu \mathrm{g}$.

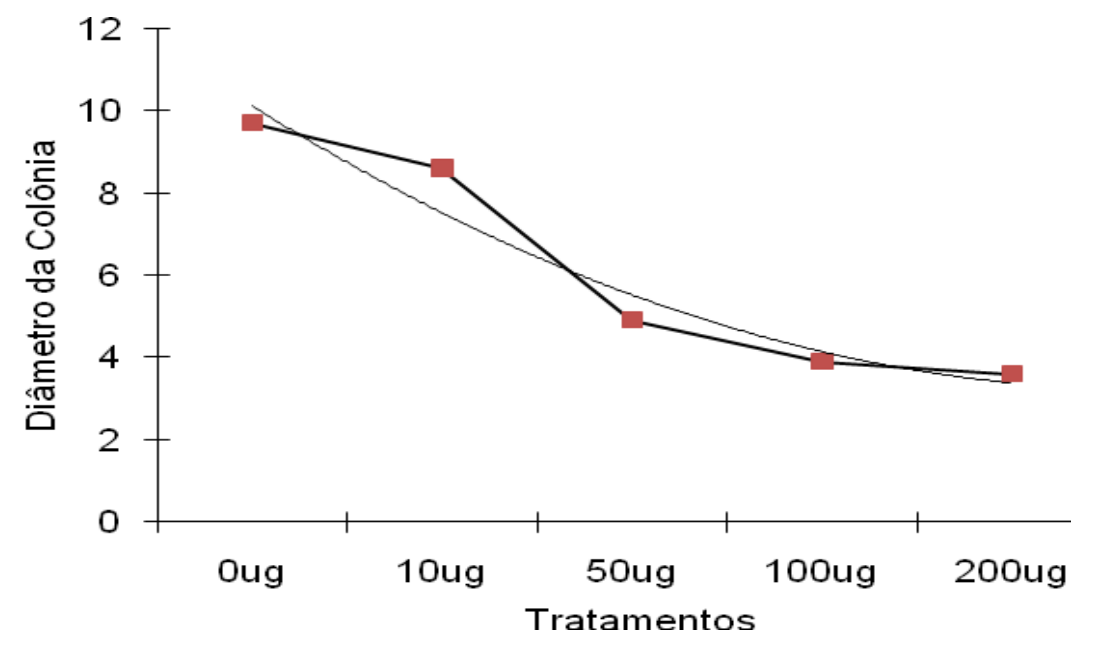

Figura 1. Análise de regressão do efeito do óleo de Neem sobre o crescimento micelial de

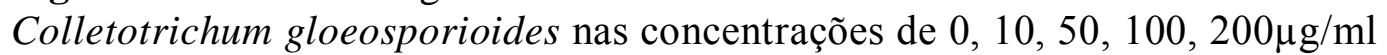

Vivas et al. (2006) constataram que o efeito do óleo essencial de capim-santo promoveu inibição em $100 \%$ do crescimento micelial do fungo Colletotrichum acuntatum, nas concentrações superiores a $100 \mu \mathrm{L} / \mathrm{mL}$.

Pereira et al. (2007), testando diferentes concentrações de óleo essencial de $C$. citratus e E. citriodora sobre os fungos $C$. musae e $C$. gloeosporioides, causadores da podridão da banana, e encontraram inibição em $100 \%$ do crescimento micelial do $C$. gloeosporioides na concentração de $1000 \mu \mathrm{L} / \mathrm{L}$ a $1500 \mu \mathrm{L} / \mathrm{L}$ e do $C$. musae na concentração de $1500 \mu \mathrm{L} / \mathrm{L}$. Na concentração de $1500 \mu \mathrm{L} / \mathrm{L}$ o óleo essencial de E. citriodora proporcionou inibição de $61 \%$ do C. gloeosporioides e $84 \%$ do C. musae.

Para o óleo de Neem a $200 \mu \mathrm{g} / \mathrm{mL}$ houve inibição micelial sobre Colletotrichum gloeosporioides de $61 \%$ comparado com a concentração de $0 \mu \mathrm{g} / \mathrm{mL}$ (testemunha), é o que mostra na (Tabela 1 e Figura 2). Sendo assim obtendo o mesmo resultado de Pereira et al. (2007) com óleo essencial de E. citriodora 

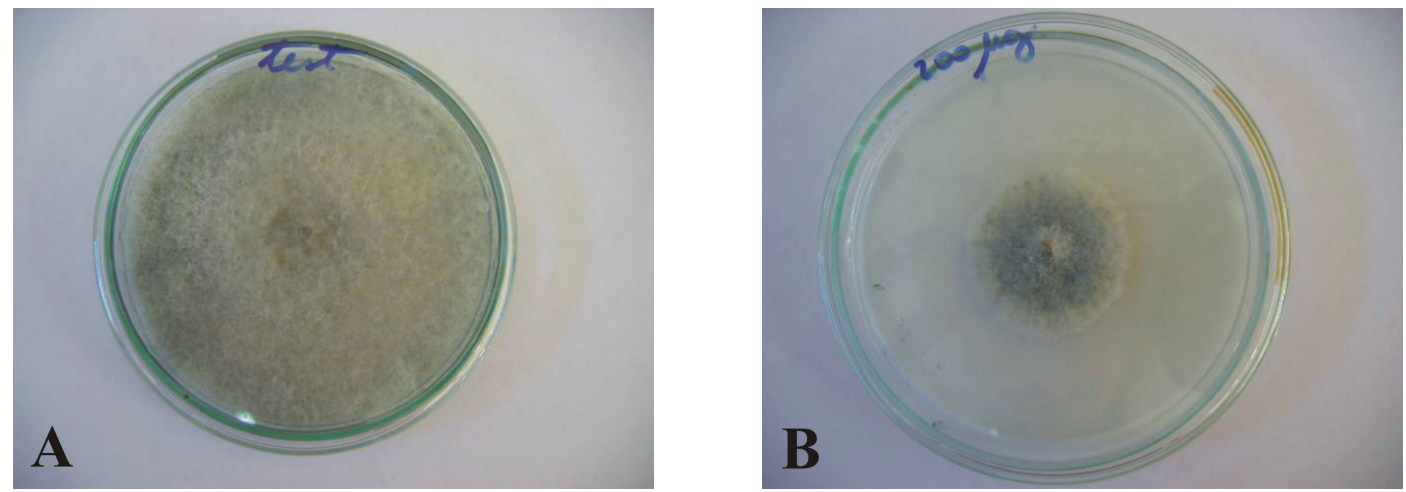

Figura 2. Crescimento micelial de C. gloeosporioides em meio BDA. Letra (A) 0 de concentração e (B) concentração de $200 \mu \mathrm{g} / \mathrm{ml}$ de óleo de Neem.

Na figura 3 mostra a inibição da germinação dos conídios de C. gloeosporioides de acordo com a concentração. Possivelmente o óleo de Neem, na concentração de $200 \mu \mathrm{g} / \mathrm{ml}$, pode vir a ser usado como alternativa no controle da antracnose como controle biológico integrado às técnicas convencionais da cultura.
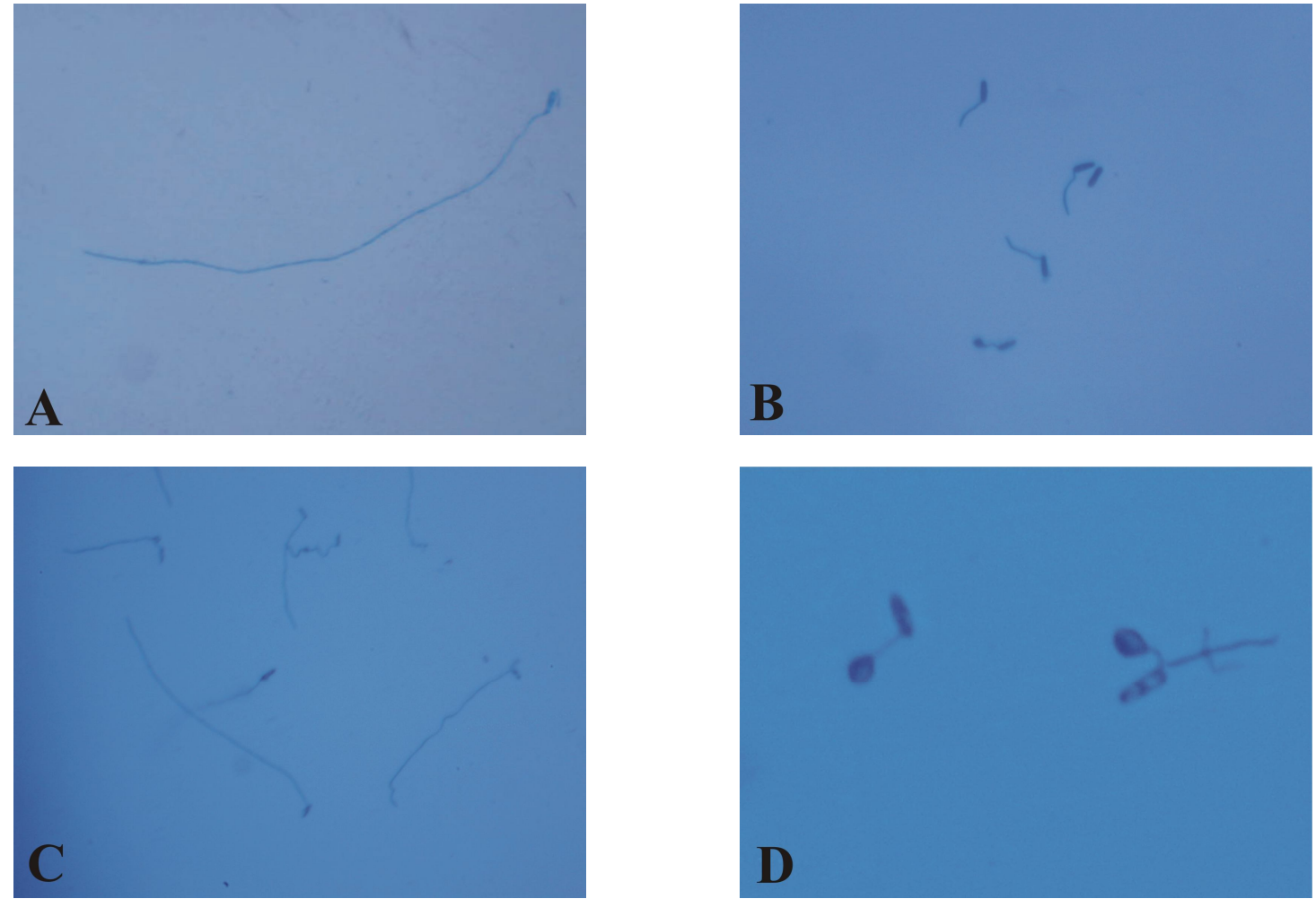

Figura 3. Imagem ao microscópio óptico em aumento de $400 \mathrm{X}$ de conídio de $C$. gloeosporioides em germinação pelo efeito do óleo de Neem.(A) 0 de concentração com tubo germinativo, (B) concentração de $50 \mu \mathrm{g} / \mathrm{ml}$, (C) concentração de $100 \mu \mathrm{g} / \mathrm{ml}$ e (D) concentração de $200 \mu \mathrm{g} / \mathrm{ml}$ com formação do apressório.

Uma perspectiva para aplicação dos resultados deste trabalho está na elaboração de produtos fitossanitários naturais para o sistema orgânico de produção agropecuária. O Ministério da Agricultura Pecuária e Abastecimento (Brasil, 1999) define os produtos orgânicos como todos aqueles produtos em que se adotam tecnologias que aperfeiçoem o 
uso de recursos naturais e sócio-econômicos, respeitando a integridade cultural e tendo por objetivo a auto-sustentação no tempo e no espaço, a maximização dos benefícios sociais e a minimização da dependência de energias não renováveis.

\section{CONCLUSÃO}

Pelo exposto evidencia-se que, mesmo não obtendo um resultado de inibição 100\%, o óleo de Neem apresentou um resultado significativo. Assim, devido à eficiência de controle do fungo com o uso de óleos essenciais, mais trabalhos adicionais serão necessários para avaliar novas concentrações dos óleos sobre o crescimento miceliano e germinação dos conídios de C. gloeosporioides a partir de $200 \mu \mathrm{g} / \mathrm{ml}$ para estabelecer concentrações inibitórias seguras e podendo testar a sua eficácia no controle da antracnose em condições de campo. Os resultados obtidos neste trabalho, pode-se concluir que o óleo de Neem, além de ser um produto biológico natural, apresenta potencial de controle in vitro significativo.

\section{REFERÊNCIAS}

BASTOS, C.N.; ALBUQUERQUE, P.S.B. Efeito do óleo de Piper aduncum no controle em pós-colheita de Colletotrichum musae em banana. Fitopatologia Brasileira. v.29, p.555-557, 2004. Disponível em http://www.scielo.br/pdf/fb/v29n5/21869.pdf; Acesso em: 19 set. 2009.

BASTOS, C. N. Efeito do óleo de piper aduncum sobre crinipellis perniciosa e outros fungos fitopatogênicos. Fitopatologia Brasileira, Belém, v. 3, n. 22, p.441-443, 15 maio 1997.

BRASIL, Ministério da Agricultura Pecuária e Abastecimento. 1999. Instrução Normativa No 007, de 17 de maio de 1999. Disponível em http://www.agricultura.gov.br/. Acesso em 02 de abril de 2011

FURTADO, E. L.; SILVEIRA, A.P.; LOPES, M. E. B. M. Controle de patógenos associados ao painel de sangria da seringueira. Summa Phytopathologica, Jaguariuna, v.17, n.1: 31p.1991.

GASPAROTTO, L. et al. Doença da seringueira no Brasil. Brasília: EMBRAPA,1997. p.711.

GASPAROTTO, L. et al. Enfermidade da seringueira no Brasil. Manaus: EMBRAPACPAA, 169p. 1990. ( EMBRAPA-CPAA, Circular Técnico, 3)

ISLA sementes, 2010. http://www.isla.com.br/cgi-bin/detalhe.cgi?id=690. Acesso em 04 abr. 2011.

MARTINEZ, S.S. O Nim: Azadirachta indica natureza, usos múltiplos, produção. Londrina: IAPAR, 2002. 
MEDICE, R.et al.. Óleos essenciais no controle da ferrugem asiática da soja Phakopsora pachyrhizi Syd, \& P. Syd. Ciência agrotecnológica, v.31, n.1, p. 83-90, 2007.

MOSSINI S.A.G; KEMMELMEIER, C. A árvore Nim (Azadirachta indica A. Juss): Múltiplos Usos. Acta Farm. Bonaerense v,24.p.139-48, 2005. Disponível em: http://www.preservamundi.com.br/artigos/neem multiplos.pdf.

PEREIRA, M. C.; VILELA, G. R.; COSTA, L. M. A. S. Inibição do desenvolvimento fúngico através da utilização de óleos essenciais de condimentos. Ciência Agrotecnológica, v.30, n.4, p. 731-733, 2006.

SILVEIRA, A. P.; FURTADO, E. L.; LOPES, M.E.B.M. Antracnose da seringueira no Estado de São Paulo. 3p. 1989. (Comunicado Técnico).

SILVEIRA, A. P. da; FURTADO, E. L. ; LOPES, M. E. B. de M. Antracnose: nova doença do painel de sangria da seringueira. Summa Phytopathologica, Jaguariúna, v. 18, n. 2, p. 196200, 1992.

TAVARES, G.M.; SOUZA, P.E. Efeito de fungicidas no controle in vitro de colletotrichum gloesporioides agente etiológico da antracnose do mamoeiro (carica papaya 1.). Ciências Agrotec, Lavras, v. 29, p.52-59, 2004. Disponível em: http://www.scielo.br/pdf/cagro/v29n1/a06.pdf; Acesso em: 19 set. 2009.

VIVAS, M.et al. Inibição in vitro do crescimento micelial de Colletotrichum acutatum por extrato bruto aquoso e óleo essencial de Cymbopogon citratus (DC) Stapf e Eucalyptus citriodora Hooker. Fitopatologia Brasileira, v.31, p.265, 2006. 
